\title{
AN ANALYSIS OF MAINTENANCE PERFORMANCE SYSTEMS IN THE SOUTH AFRICAN MINING INDUSTRY
}

\author{
R.L.M. Kotze ${ }^{1}$ \& J.K. Visser ${ }^{2 *}$ \\ ${ }^{1,2}$ Department of Engineering and Technology Management \\ University of Pretoria, South Africa \\ ${ }^{2}$ krige.visser@up.ac.za
}

\begin{abstract}
The measurement of performance is an essential part of the management process. The planning function usually defines the goals and objectives for the business enterprise or division of the enterprise. The control function should monitor the performance measures and establish corrective action if actual performance deviates significantly from planned performance. Maintenance performance measurement is therefore essential to ensure that maintenance objectives are achieved, and that maintenance adds value for the company. The objective of this paper is to discuss the findings of a project that investigated aspects of the maintenance performance system of a number of mining companies in South Africa. The findings of a survey indicated that maintenance performance management is not yet used to its full potential in the mining industry.
\end{abstract}

\section{OPSOMMING}

Die meting van prestasie is ' $n$ noodsaaklike deel van die bestuursproses. Die beplanningsfunksie defineer normaalweg die doelwitte vir die organisasie of divisie van die organisasie. Die beheerfunksie monitor die prestasie en bepaal of korrektiewe aksie nodig is wanneer die werklike prestasie noemenswaardig afwyk van die beplande prestasie. Prestasiemeting in instandhouding is dus noodsaaklik om te verseker dat die doelwitte vir die instandhoudingsafdeling bereik word en dat instandhouding waarde toevoeg vir die organisasie. Hierdie artikel bespreek die resultate van 'n projek wat verskeie aspekte van die prestasiestelsel van 'n aantal mynmaatskappye in Suid-Afrika ondersoek het. Die vernaamste bevinding van die projek is dat prestasiebestuur in instandhouding nog nie ten volle benut word deur verskeie mynmaatskappye in die mynbou-industrie nie.

${ }^{1}$ The author was enrolled for the M.Eng. (Engineering Management) degree in Department of Engineering and Technology Management, University of Pretoria.

* Corresponding author. 


\section{INTRODUCTION}

\subsection{Background}

In today's global world, companies are becoming more and more competitive. Money for profits and for welfare drives all decisions. De Groote [1] views maintenance as an integral part of an organisation's long-term profitability, and which has increasingly become part of a total performance approach. This means that maintenance is no longer seen as a cost centre, but as a department that can add value through long-term equipment reliability and availability. Machines and equipment need to be maintained or repaired to keep performing safely and efficiently to their intended capacity specification or design. Mining is the largest industry in the primary economic sector of South Africa [2], and one of the cornerstones of the South African economy. Mining is very capital intensive, and in conjunction with extreme conditions, maintenance cost is often a high contributor to the total operational cost of a mine. Profits can be increased if maintenance is done more efficiently and effectively. This will have a direct impact on company profits, economic growth, and global competitiveness.

Performance management is an integral part of the management of any organisation. This is the feedback loop to managers at all levels to ensure that the energy of the organisation is focused on the same objectives and goals. In performance measurement, you usually get what you measure. Measure the wrong things, and it will result in good performance in the wrong areas (which is not efficient). Measure things wrongly (which also is not effective) and people will do anything to manipulate measures to achieve the outcome they want. Maintenance performance indicators (MPIs) are used to monitor the performance of the maintenance system and to initiate improvement areas. It is imperative that these MPIs are derived and used in the right way to unlock the full potential of maintenance management in contributing to to the organisation's financial performance for the present and the future.

\subsection{Status of maintenance in the South African mining industry}

The mining industry is an integral part of the South African economy. The output of the mining industry contributed 9,5\% of gross domestic product in 2008 [3]. The South African mining industry can be divided into diamonds, gold, platinum-group metals, ferrous and non-ferrous metals, coal, and industrial and miscellaneous commodities. South Africa's mining industry also plays an important role in the global mining industry, and is the primary producer of some of the most valuable commodities like platinum, chrome ore, and vanadium. The reserves of many commodities place them in the top ten positions in the world.

The large number and variety of physical assets used in the mining industry result in a high maintenance cost for most mines in South Africa and in the world. Campbell [4] indicates that the maintenance cost for mining is generally $20-50 \%$ of the total operational or production cost. Financial indicators are therefore needed for the maintenance department to ensure that costs are adequately measured and controlled. However, as indicated by Kaplan \& Norton [16], the maintenance department should also use different indicators to measure other perspectives of the department.

Safety and environmental management plays a key role in the mining industry. Because of heavy equipment, labour intensive tasks, and geological uncertainties, incidents are more likely to occur in the mining industry than in other industrial sectors. Major hazards and unwanted events with loss of life increase pressure at all levels of the organisation, and production losses result when these events occur. The Department of Minerals and Energy puts pressure on mines by enforcing the Mine Health and Safety Act and its regulations. The maintenance department is legally appointed to keep equipment safe to operate, maintain buildings and structures, and maintain safety devices and systems (Regulation 2.13.4.1 of the Minerals Act, Act 50 of 1991). Mining in South Africa had a poor safety record until about 2006, when all mining companies introduced safety initiatives to progress to safe 
production and zero harm. Maintenance departments are part of these initiatives, and risk assessments are now used to derive safe maintenance practices and procedures.

\subsection{Research problem}

A preliminary investigation suggested that very limited literature and research are available on maintenance performance measurement, specifically in the mining industry. Any research that contributes to knowledge and information about how to use MPIs effectively in the mining industry can assist in the overall performance of maintenance.

The preliminary investigation also suggested that there might be a gap between the way in which the selection of maintenance performance indicators and the implementation of such performance measures could be done more effectively, on the one hand, and the actual situation in the mining industry of South Africa on the other. The concern is that maintenance performance measurement is not used to its full potential: many facets are poorly managed. MPIs are not developed and identified from a maintenance strategy in a formal or structured way. There is a further perception that performance management is used and applied incorrectly in many situations, and that this leads to the wrong behaviour. It seems that the MPIs measured are reactive, and do not focus on all the maintenance aspects to get a balanced perspective of performance with maximum efficiency.

\subsection{Research objectives}

The objective of this study was to determine whether maintenance departments of mines in South Africa use performance measurement efficiently and effectively. To use MPIs efficiently (to measure and manage the right things), it had be determined whether the maintenance departments used a structured approach to derive MPIs, and whether they identified the correct areas to measure. This would ensure a balanced set of indicators to monitor performance and to make the right decisions. To use MPIs effectively (to measure and manage things correctly), it also had to be determined whether maintenance departments applied these MPIs correctly. In order to address the research problem effectively, the following propositions were formulated:

- Proposition 1: MPIs used in mining are not derived or developed from the maintenance strategy and objectives through a structured process.

- Proposition 2: Maintenance performance management is not applied effectively in the mining industry.

- Proposition 3: MPIs used in mining do not address all the important categories of maintenance management.

- Proposition 4: MPIs used in mining maintenance have a high focus on lagging or reactive indicators.

- Proposition 5: Maintenance performance measurement is not used effectively and efficiently to create value to its fullest potential in the mining maintenance environment.

\subsection{Limitations of study}

The mining industry in South Africa is more than 150 years old. One can therefore expect that the age of mines currently in operation, as well as the technology used, will differ vastly. The level and associated cost of maintenance will depend on the age of the equipment, the technology used at the mine, and the level of mechanisation in the mine. Regarding mechanisation, some mines in South Africa still use traditional or conventional mining equipment, while some of the younger mines use remote-controlled mechanised vehicles and other equipment. No attempt was made in this study to differentiate between mines in terms of their age or level of mechanisation. The results can therefore not be generalised across all mines in South Africa.

The majority $(\sim 70 \%)$ of the respondents in this study were engineering managers, and more than $70 \%$ of the respondents had in excess of eight years' experience. The respondents could have quite different views of what maintenance management is within the organisation, compared with junior workers or workers with less experience in maintenance 
management. In addition, the role of an 'engineering manager' could differ from one company to another. This study did not compare the views of the different levels within the organisation, or the fact that engineering managers might have different roles within their respective organisations or mines.

\section{LITERATURE}

Many different approaches to, and models and concepts of, maintenance performance management are found in literature. This section provides a brief discussion of some of the most important literature sources on the topic of maintenance performance management and indicators. The sources are discussed in respect of four areas that are relevant to this study.

\subsection{Process to identify performance indicators}

Tsang [5] describes a structured approach to identify and derive performance indicators for maintenance as part of a performance management process. The process starts with the development of the corporate strategy, from which follows a maintenance strategy. The maintenance strategy comprises the formulation of maintenance objectives as well as measures and targets. From these maintenance objectives, action plans should follow to achieve the objectives. Performance measurement is required to close the control loop. This process must be measured using MPIs to ensure that the strategy is on track. Various other sources - for example, Mather [6], Tsang [7], Wireman [8], Mitchell [9], Parida \& Kumar [10], Kutucuoglu et al. [11], Alsyouf [12], and Coetzee [13] - proposed that performance management should be underpinned by a formal and structured process. Performance management for maintenance should also be linked to the corporate goals and objectives.

Wireman [8], Parida [14], Mather [6], Mitchell [9], Visser \& Pretorius [15], and Kutucuoglu et al. [11] emphasise the importance of different MPIs for different hierarchical levels of the organisation. According to Wireman [8], a top-down approach should be followed to derive MPIs from the top or corporate level through to the lowest organisational levels. Because the indicators on the corporate level have a long-term focus and vision, it is necessary to make sure that all indicators for the lower organisational levels are also tied to the long range corporate vision. This will ensure that the corporate strategy and direction is followed and supported by every organisational level.

\subsection{Balanced approach for maintenance indicators}

The importance of performance indicators to address various aspects or dimensions of maintenance management was emphasised by most sources. Wireman [8] identified performance indicators for five hierarchical levels of the business enterprise, and for 11 maintenance-specific processes.

Tsang [7] applied the balanced scorecard approach of Kaplan \& Norton [16] to the management of maintenance by addressing four perspectives of strategic management. Indicators should be defined that focus on the financial, customer, internal business processes, and learning and growth perspectives.

Mather [6] developed a maintenance scorecard model using six fundamental questions to ensure a balanced approach to all aspects of asset management. Mitchell [9] and Kutucuoglu et al. [11] identified five maintenance performance categories each, to ensure a balanced set of MPIs.

Many authors also emphasised the importance of achieving a balance between lagging and leading MPIs - for example, Parida [14], Mather [6], Tsang et al. [17]), Tsang [5], Hedding [18], and Army [19]. Mather [6] found that the purpose of leading indicators was to highlight opportunities for continuous improvement.

\subsection{Employee involvement}

Tsang [5] emphasises the importance of the impact of employee behaviour on the success 
of performance measurement. Employees need to be involved and participate from the beginning in the identification and rollout of performance measures. Innovation and improvement will automatically be more natural and efficient due to empowerment, commitment, and ownership. Effective MPIs measure results that managers and workers can control and change. The sense of control, ownership, and contribution is very important to the overall optimisation and improvement process. It is critical that employees at each level of the organisation understand the metric for which they are responsible, and why this metric is important. Army [19] also argued that employee behaviour is an important aspect that should be addressed by using leading indicators.

\subsection{Maintenance performance indicators in mining}

Few journal articles on the application of maintenance performance indicators (MPIs) in the mining industry have been published. Visser \& Pretorius [15] discussed the development of MPIs at various hierarchical levels for a coal mine. The maintenance manager of a mine needs 5-10 key performance indicators for the total maintenance system or department. Hollhumer \& Visser [20] also investigated the application of MPIs in the mining industry, and found that the operations surveyed (platinum and gold mines) used a very similar set of maintenance performance indicators.

\section{RESEARCH FRAMEWORK}

The purpose of an indicator in maintenance is to provide information on the status of certain aspects of the performance of the maintenance system. An effective indicator should enable management to improve the performance. It provides a 'snapshot' of the performance at a specific point in time. The mining maintenance industry needs to be investigated to see whether performance measurement is used effectively and efficiently. There is a concern that the most effective MPIs are not used, they are not identified correctly, and are not applied correctly. The framework outlined in Figure 1 was developed to determine whether performance management is used to its full potential.

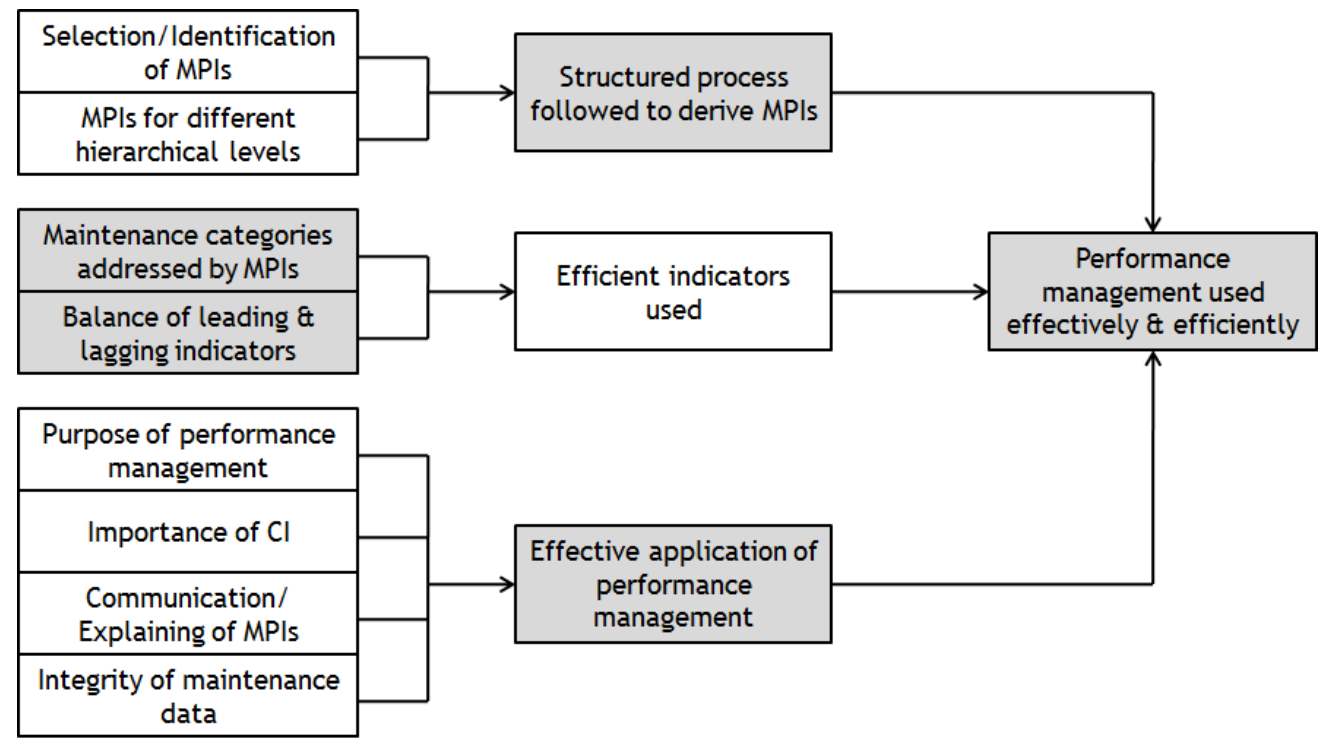

Figure 1: Framework to determine the use of performance measurement

The first area of the framework investigates whether a structured process is followed to derive MPIs. The way in which MPIs are selected plays a crucial role in performance management. The maintenance strategy needs to be determined from the corporate goals and objectives. MPIs need to be derived from the maintenance strategy through a formal process. This should be a participative process, where the aim is to create ownership as 
well as a sense of control and contribution by employees. Another important factor is that MPIs should be identified for the various hierarchical levels of the organisation. These MPIs should be relevant for the timeline and role in strategy at each specific level. MPIs should be linked through the different levels to the top level MPIs, and thus linked to the corporate objectives.

The next area of the framework determines whether the MPIs selected are the most efficient indicators. To ensure a balanced approach, MPIs need to address all important maintenance management categories. Seven categories have been identified from the literature: maintenance workflow; equipment/process performance; organisational culture; financial performance; continuous improvement/innovation; safety, health \& environment performance; and customer involvement/satisfaction. Another important facet is the identification of leading indicators to monitor performance areas proactively.

Indicators need to be selected that will lead to the correct employee behaviour and ensure the desired results. Some reactive indicators are necessary to confirm the performance. Lagging indicators are measures that focus on results that are achieved at the end of a time period - for example, at the end of the month or year. These indicators are also referred to as 'key results indicators'. Examples in the maintenance environment are availability, reliability, and maintenance cost. Leading indicators are indicators that lead to the performance of lagging indicators. These are frequently measures that relate to intermediate processes in the total business process. Examples in the maintenance environment are maintainability, number of repeat jobs versus total number, and backlog.

The next area to be investigated is the effective application of performance management to create optimum value. The areas in which performance management are used will indicate how well the role of performance management is understood in an organisation. Performance management should be used to track the maintenance strategy, highlight opportunities for improvement, and give feedback and rewards to employees. It should not primarily be used to measure past performance and declare deviations. The next area, according to Figure 1, is continuous improvement. To maximise value, organisations need to use and exploit improvement and innovation. Another important facet is communication and the training of employees on selected MPIs. Employees need to understand the rationale and interpretation of selected MPIs to create a sense of control, contribution, and ownership. The final element according to Figure 1 is the integrity of maintenance data. The integrity of maintenance systems and data, as well as how easy it is to acquire and rework, indicates how important performance management is perceived to be in the organisation.

By investigating the different areas, it can be determined whether an organisation is using maintenance performance management effectively and efficiently to create maximum value.

\section{METHODOLOGY}

\subsection{Research strategy}

The research population for the sample was all the current operational mines in South Africa. The commodities investigated were diamonds, gold, platinum group metals (PGMs), coal, ferrous metals, and nonferrous metals. The selected group represents more than $92 \%$ of the whole population. The selected group provided an acceptable degree of reliability and accuracy for the survey. The questionnaire was developed by translating research variables into questions from the framework given in Figure 1. The first part of the questionnaire gathered the domestic circumstances and organisational context. An international web-based survey tool, SurveyMonkey, was selected to collect responses.

All the variables identified for the research section were discrete. The measurement scales varied between nominal, ordinal, and Likert scales. Data was grouped and basic statistical calculations were done. This included an average rating, mode, and standard deviation. Pie or bar charts were used to represent univariate distributions. 


\subsection{Data collection and analysis}

The data was collected by sending e-mail messages to the engineering managers of 172 mines. The final response rate was $42 \%$ of the sent messages ( 72 replies out of 172 recipients). The response rate was sufficient to analyse and derive valid conclusions for the industry, as it represents about $39 \%$ of the total identified population ( 72 out of 186 mines). The questionnaires were mostly completed and returned by engineering managers (71\%); the distribution of their experience in maintenance management is indicated in Figure 2.

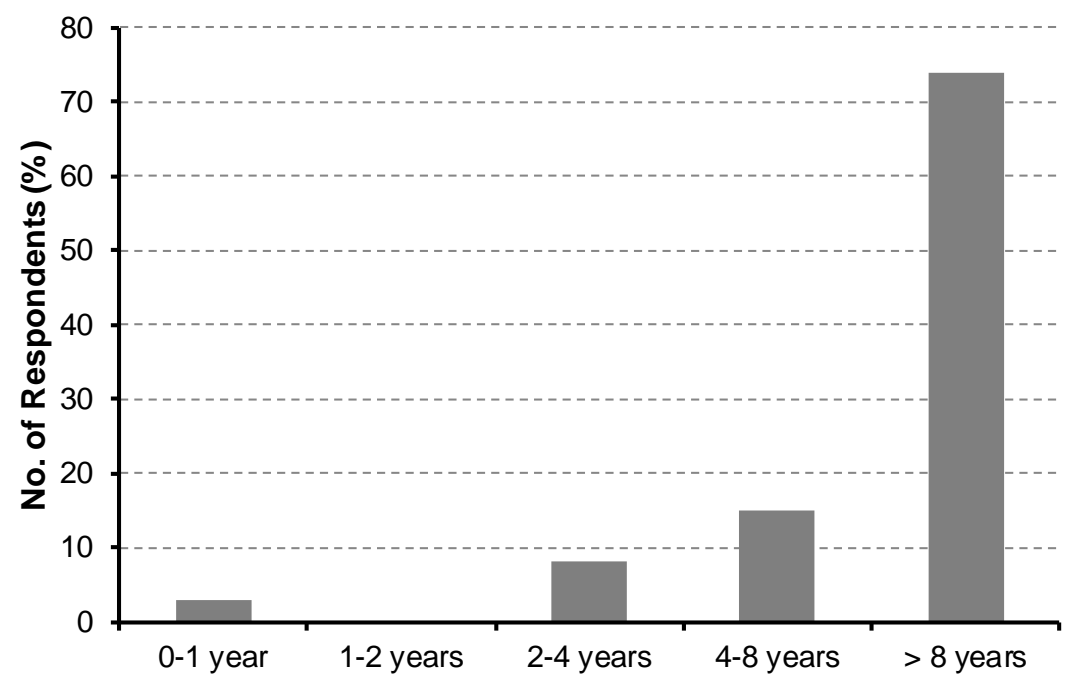

Figure 2: Distribution of experience of the respondents

Respondents associated with different types of operations were targeted and invited to fill in the questionnaire; the final distribution of the respondents is given in Figure 3.

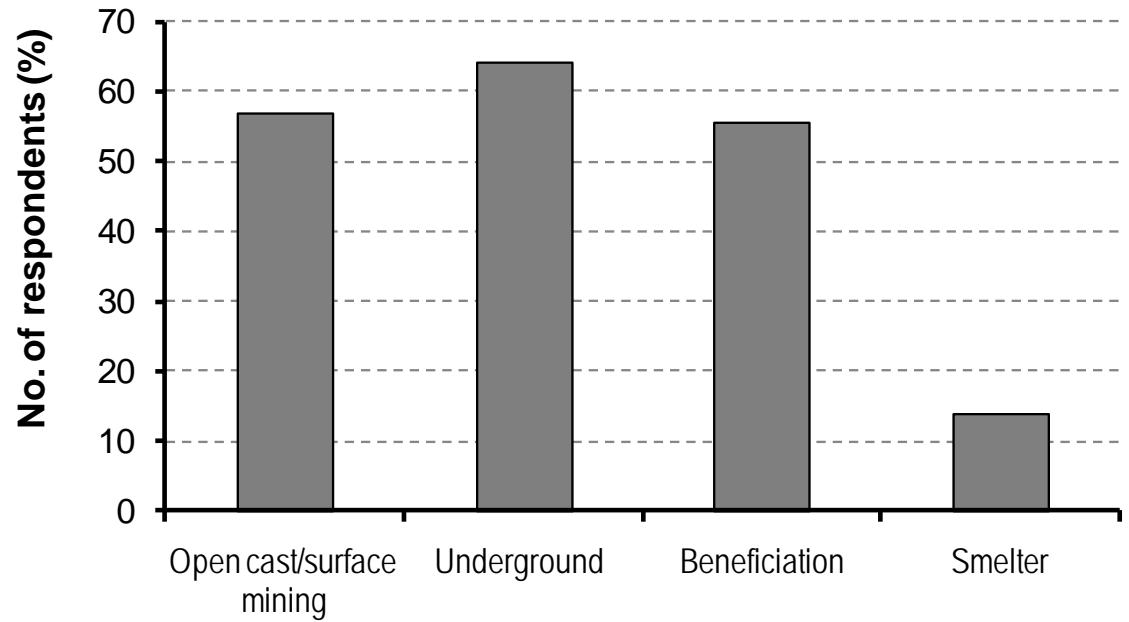

Figure 3: Distribution of types of operation

Fourteen percent of the respondents indicated that smelter operations were done on the site, but more than $50 \%$ of the mines were involved in each of open cast mining, underground mining, and beneficiation. 
Respondents also indicated which commodities are produced by the mine, with the results shown in Figure 4.

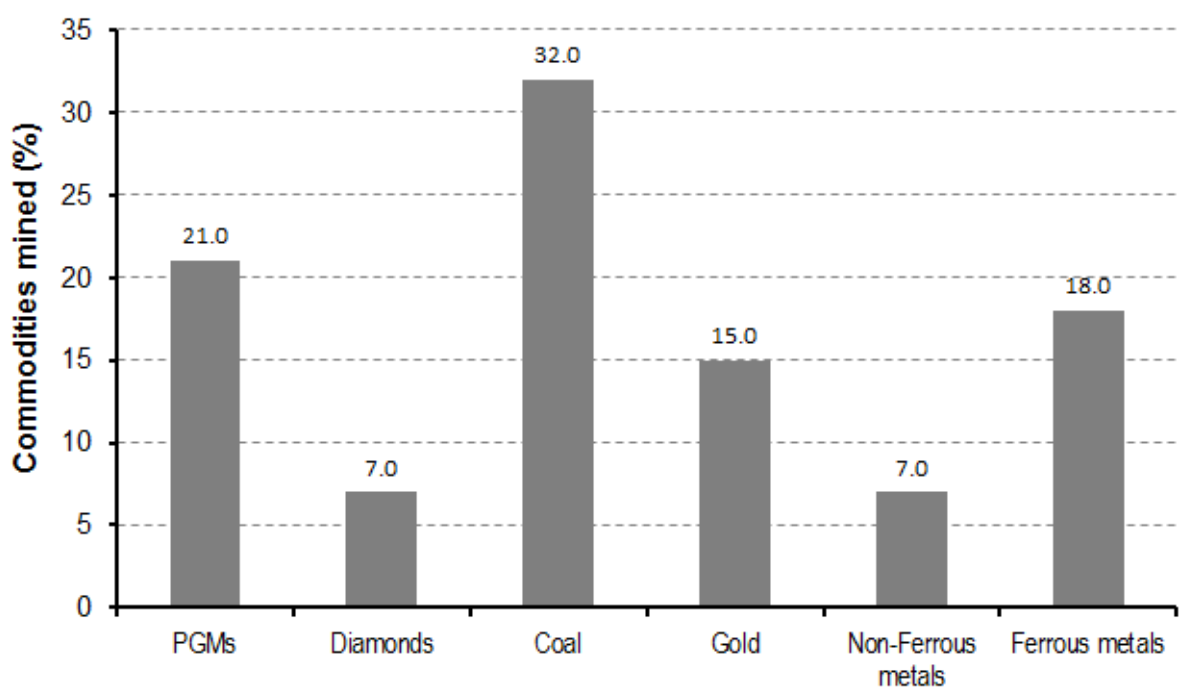

Figure 4: Distribution of commodities mined

As seen in Figure 4, the largest number of respondents was involved in coal mining - i.e. $32 \%$ of the total number of 72 respondents.

\section{RESULTS}

\subsection{Introduction}

The data collected through the SurveyMonkey internet tool was grouped and analysed with a spreadsheet. The results are mainly presented as bar charts or pie charts for easy interpretation. The following aspects are presented in this paper.

- What method was used to identify maintenance performance indicators, if any?

- Which indicators, out of a given list of 32 , are the most important?

- Which categories of indicators are the most important?

- For what purpose are maintenance indicators used?

- How are the indicators communicated to the different levels in the organisation?

\subsection{Selection Process for MPIs}

Respondents were asked to indicate how maintenance performance indicators were identified, developed, and selected for the maintenance division. Eight options or methods relating to the selection method for MPIs were provided in the questionnaire, and the respondents had to select one of the following responses for each.

- $\quad$ Not applicable (0)

- Was used, small influence on selection (1)

- Played an important role in selection (2)

- Primary approach used for selection (3)

One, two, or three points were allocated for each response, as indicated in the brackets above. The average score for all respondents was then calculated for each of the eight options. The results are shown in the bar chart in Figure 5 below. 


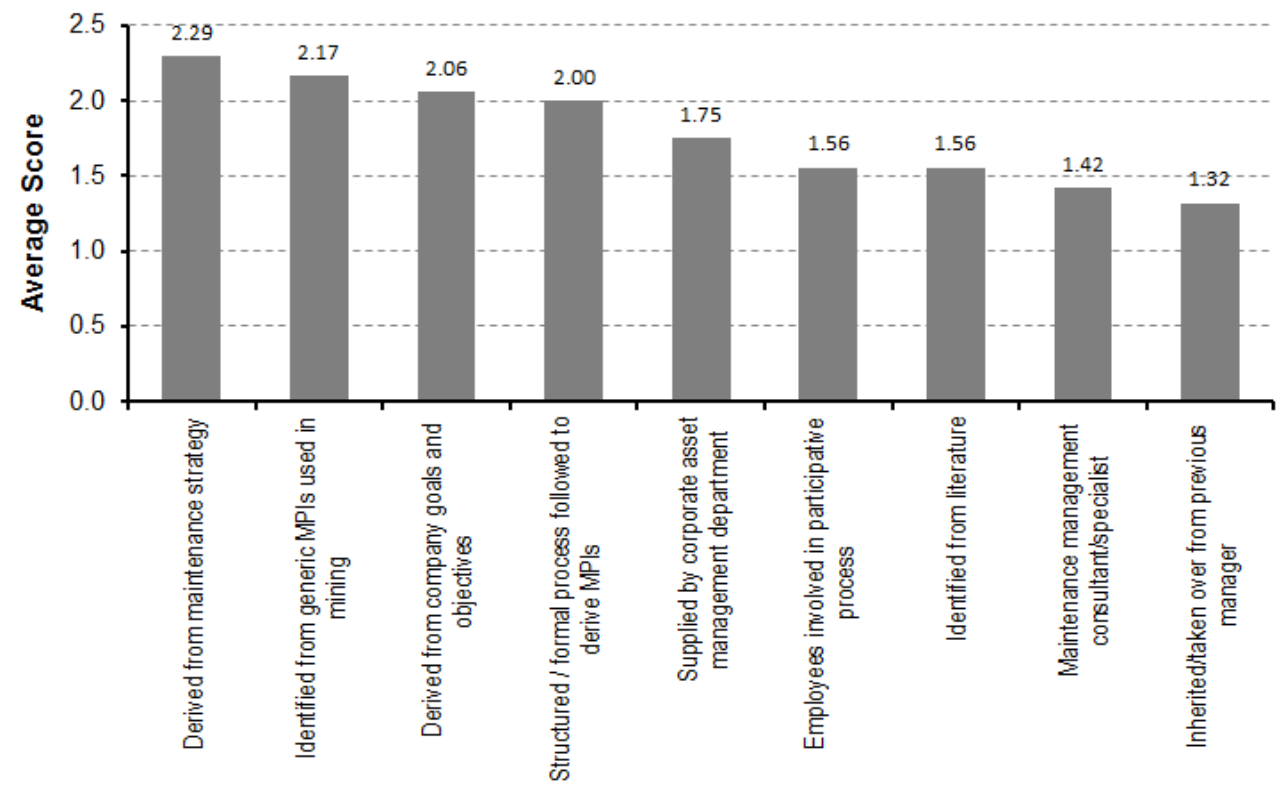

Figure 5: Method used to select maintenance performance indicators

It is seen from Figure 5 that most respondents (mines) indicated that MPIs were 'derived from the maintenance strategy'. The second-highest response was 'identified from generic MPIs used in mining'. A maintenance department that has no performance system in place will most probably take the easy way out, and make use of generic MPIs that are commonly used in the mining industry. Effective MPIs can only be established if a structured process for selection is used. The following responses are indicative of such a structured process.

- Derived from maintenance strategy

- Derived from company objectives

- Structured, formal process followed (which includes some elements of company or maintenance strategy)

These three responses were ranked $1^{\text {st }}, 3^{\text {rd }}$, and $4^{\text {th }}$, and it can therefore be stated that most maintenance departments used a structured process or method for selecting MPIs. However, the response 'identified from generic MPIs' was ranked $2^{\text {nd }}$, indicating that some maintenance departments just used generic MPIs, not a structured process. The low ranking of 'employees involved in participative process' leaves room for improvement at many mines.

\subsection{Selection of indicators for maintenance performance measurement}

A list of 32 indicators that are frequently used by maintenance organisations in all industries was provided in the questionnaire, and respondents had to indicate to what extent these indicators are used in the mining industry. The options provided in the questionnaire ranged from 'not important' (1) to 'very important' (4), while an option 'not applicable' (0) was also provided. This represents a 5-point scale. The 32 indicators provided in the questionnaire are listed in Table 1 below. A classification of those indicators that are regarded as leading and those that are regarded as lagging is also given in the table. 
Table 1: List of maintenance performance indicators given in survey

\begin{tabular}{|c|c|c|}
\hline No. & Performance Indicator & Lead/Lag \\
\hline 1 & Availability & Lag \\
\hline 2 & Safety audits score & Lead \\
\hline 3 & Reliability (MTBF or MTTF), number of breakdowns & Lag \\
\hline 4 & Plant or equipment utilization & Lag \\
\hline 5 & Lost time frequency rate & Lag \\
\hline 6 & Cost per unit, cost per hour & Lag \\
\hline 7 & $\%$ breakdowns of total downtime & Lag \\
\hline 8 & Outstanding detective tasks (safety devices testing, etc.) & Lead \\
\hline 9 & Mean time to repair (MTTR) & Lead \\
\hline 10 & Schedule compliance $=$ scheduled tasks executed/total tasks scheduled & Lead \\
\hline 11 & $\%$ of preventive maintenance (inspections, services)/total work orders & Lead \\
\hline 12 & $\%$ of unplanned maintenance vs. planned maintenance & Lead \\
\hline 13 & $\begin{array}{l}\text { \% of corrective maintenance (predictive maintenance inspections)/total work } \\
\text { orders }\end{array}$ & Lead \\
\hline 13 & Size of backlog & Lead \\
\hline 15 & $\%$ of emergency maintenance or breakdowns/total work orders & Lead \\
\hline 16 & $\%$ of equipment failures where root cause analysis is performed & Lead \\
\hline 17 & Overall equipment effectiveness (OEE) & Lag \\
\hline 18 & Component actual life (hrs) vs norm (hrs) & Lead \\
\hline 19 & $\%$ of predictive maintenance (condition monitoring)/total work orders & Lead \\
\hline 20 & Total life cycle cost (LCC) related performance indicator & Lead \\
\hline 21 & Store stock-outs & Lead \\
\hline 22 & Manpower utilisation = actual time spent on tasks/manpower hrs available & Lead \\
\hline 23 & Return on fixed assets (ROFA) or return on investment (ROI) & Lag \\
\hline 24 & Organisational culture-related indicator & Lead \\
\hline 25 & Store inventory turnover & Lag \\
\hline 26 & Manpower efficiency = actual time spent on tasks/time allowed for tasks & Lead \\
\hline 27 & $\%$ of comebacks or rework/total work orders & Lead \\
\hline 28 & Learning \& growth - training cost per employee & Lead \\
\hline 29 & Customer satisfaction - operations questionnaire & Lead \\
\hline 30 & Continuous improvement, e.g. number of initiatives/employee & Lead \\
\hline 31 & $\%$ of maintenance tasks done by operations & Lead \\
\hline 32 & Total productive maintenance (TPM) related indicator & Lead \\
\hline
\end{tabular}

The top 10 indicators (from the list of 32) that are most often used by maintenance departments in the mining industry are shown as a bar chart, sorted from highest to lowest average score, in Figure 6 below. The scores represent the average for each indicator. 


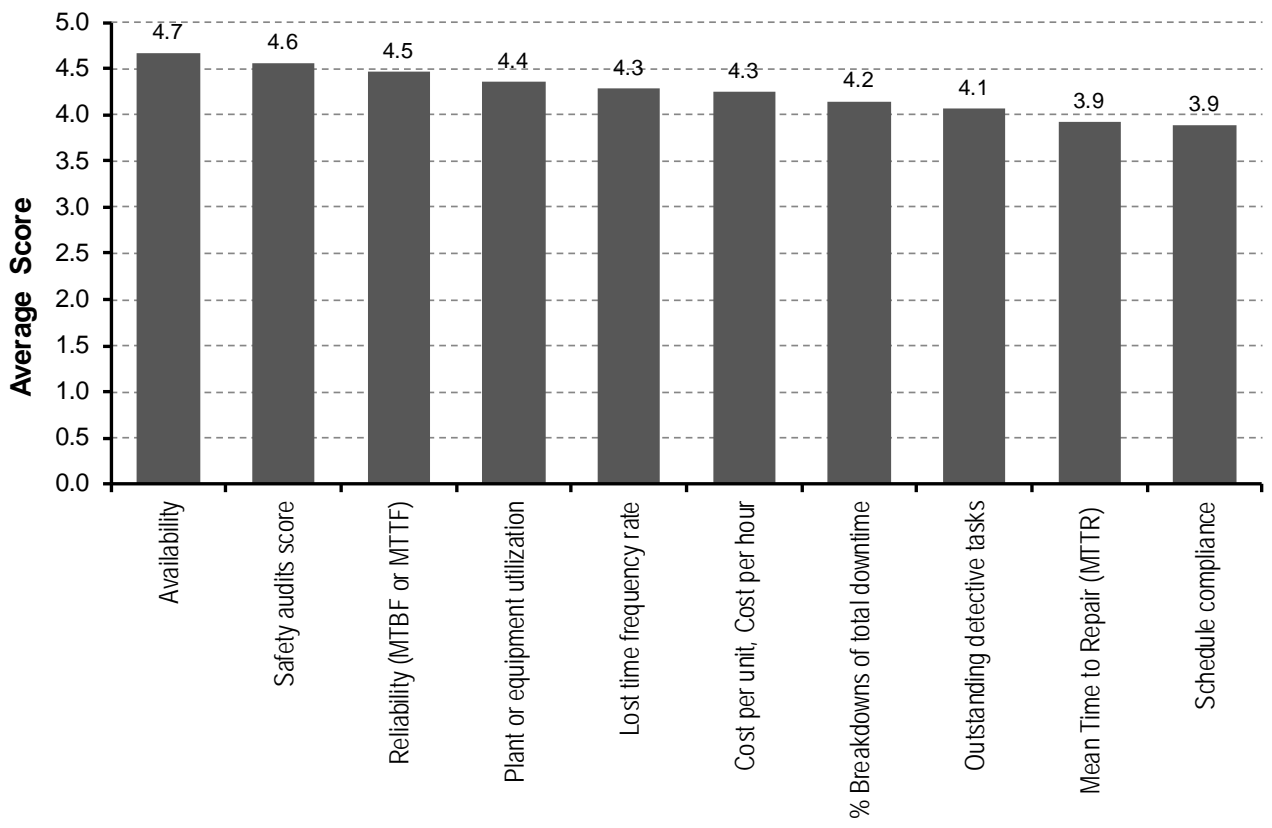

Figure 6: Indicators used most often for maintenance performance measurement

'Availability' and 'reliability' are often used by maintenance departments, since both have a large impact on the production output and therefore on the profitability of a mine. However, it seems that most maintenance departments are also safety-conscious, since 'safety audits score' and 'lost time frequency rate' are also ranked fairly high ( $2^{\text {nd }}$ and $\left.5^{\text {th }}\right)$.

Six of the nine lagging indicators in the list of 32 indicators are in the top seven rated MPIs shown in Figure 6. Only two lagging indicators are rated in the ten least-important MPIs used in mining maintenance. This is a clear indication that managers prefer to use lagging indicators and not leading indicators.

The 10 indicators that are used least often in mining are indicated in Figure 7. An interesting aspect of this graph is the low rating for 'customer satisfaction'. It seems that some maintenance departments do not like to know how the customer (operations, production) rates the performance of the maintenance department. Another interesting point in Figure 7 is the bottom three indicators - 'continuous improvement', 'maintenance done by operators', and 'TPM related indicator' - which refer to the total productive maintenance (TPM) strategy. The TPM approach is known for its quality focus, and strives to eliminate 'waste'. Excessive rework leads to more waste and degrades the quality of service provided by maintenance. It therefore seems that most mining maintenance departments in South Africa do not apply the TPM approach. The reliability centred maintenance (RCM) approach is probably preferred due to its risk-based decision-making approach.

\subsection{Maintenance categories}

Most literature sources on maintenance performance indicators - for example, Wireman [7] - classify maintenance indicators into different categories. Indicators from a number of these categories are needed to provide a balanced approach, as suggested by the 'balanced scorecard' methodology of Kaplan \& Norton [15]. The data for the performance indicators, as discussed in the previous section, was used to determine the relative usage of different categories. From the questionnaire on the performance indicators, a category was marked if the respondent allocated a value of 3 or 4 (very important) for the indicator. The combined score was converted to a percentage. Figure 8 shows the results for the seven maintenance categories. 


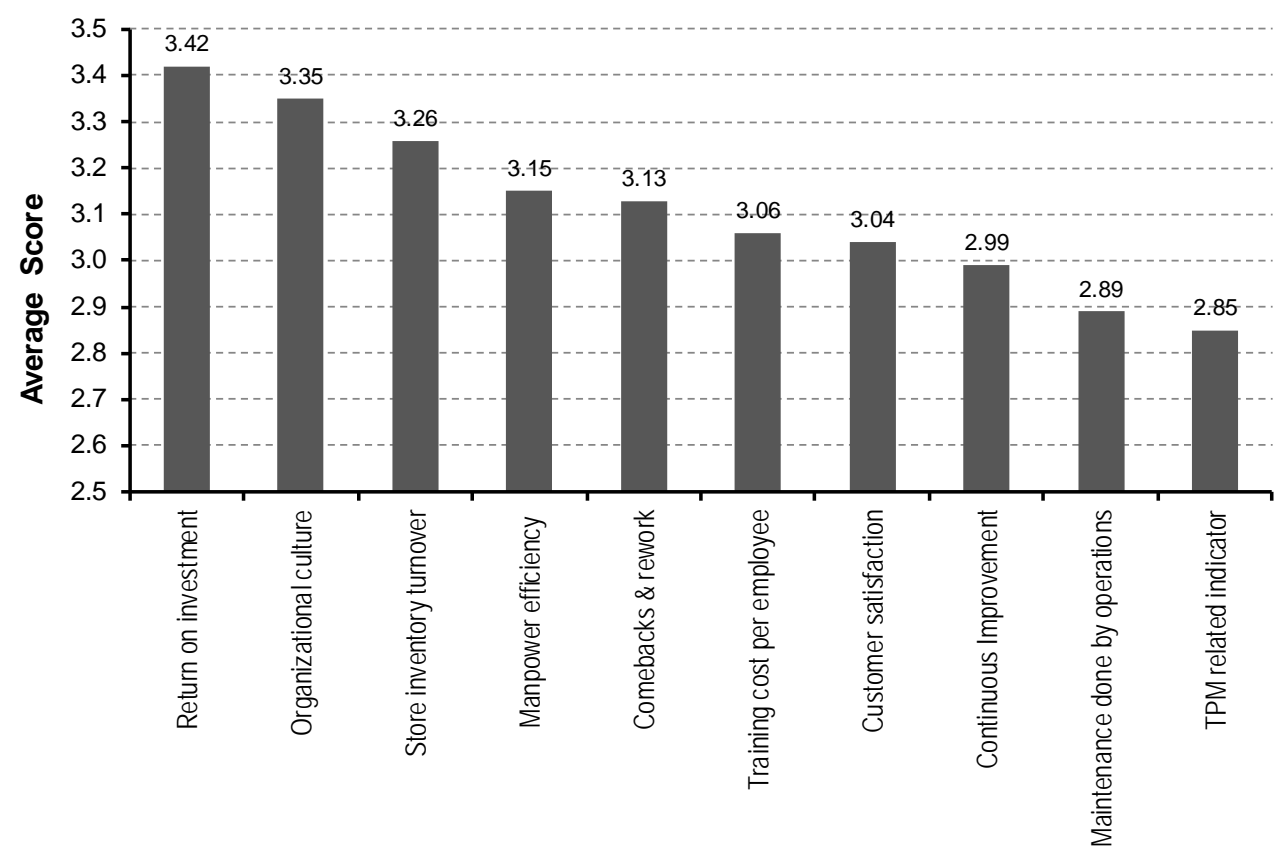

Figure 7: Indicators used least often for maintenance performance measurement

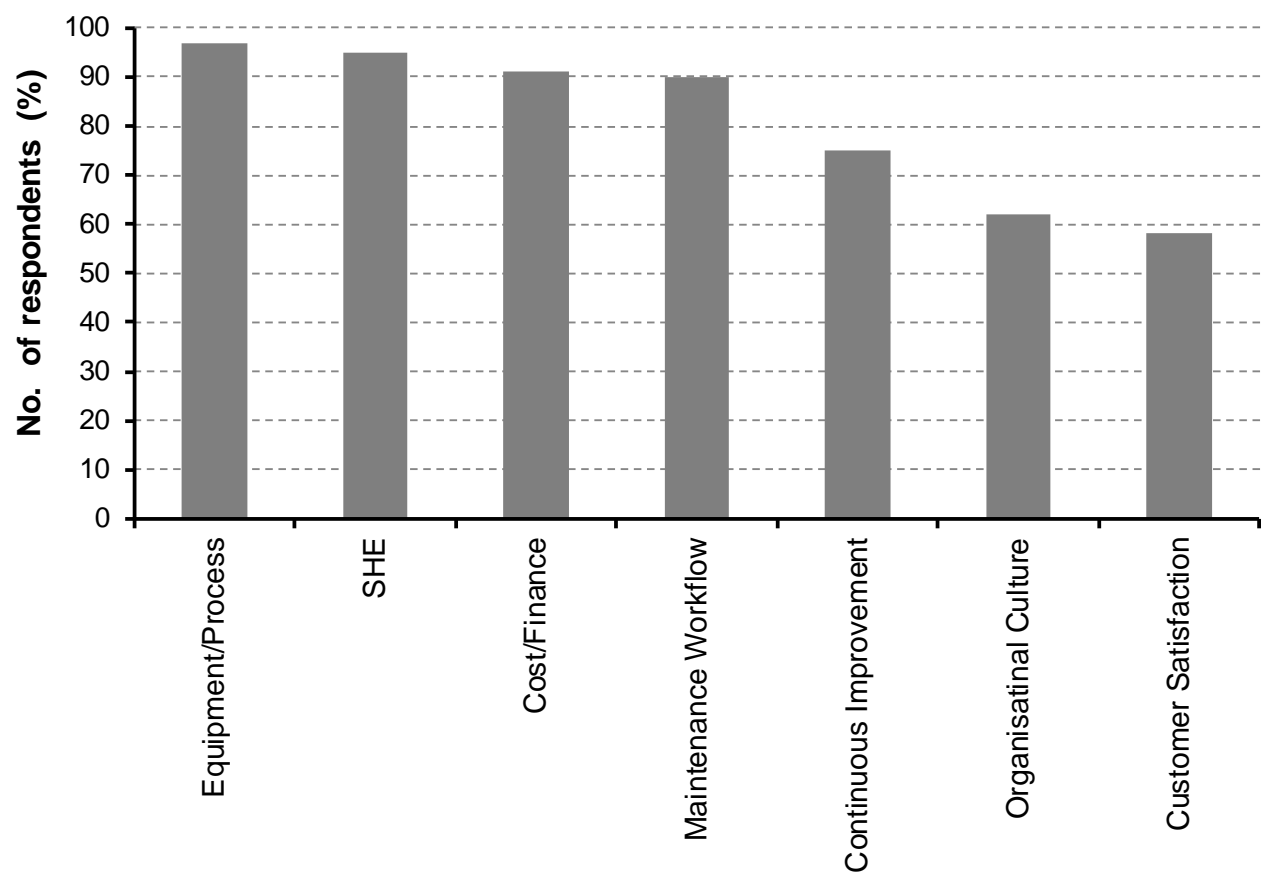

Figure 8: Categories used for maintenance performance indicators

Indicators in the top four categories of Figure 8 are often used, but indicators in the categories of 'customer satisfaction' (for example, operations satisfaction, \% maintenance done by operations, customer satisfaction index) and 'organisational culture' are used less often. This can be seen as a limitation in many maintenance departments that should strive for a more balanced approach. 
Further analysis of the results showed that only 39\% of respondents used all seven maintenance performance categories. There is therefore room for improvement.

\subsection{Application of maintenance performance indicators}

It is interesting to know how maintenance performance indicators are actually used within the maintenance departments of organisations. Respondents were asked to indicate 12 possible applications on a 4-point scale, varying from very seldom used to very frequently used. The summary results are shown as a stacked bar graph in Figure 9 below. The number of respondents (as \%) that marked 'frequently' and 'very frequently' is represented by the two bars in Figure 9.

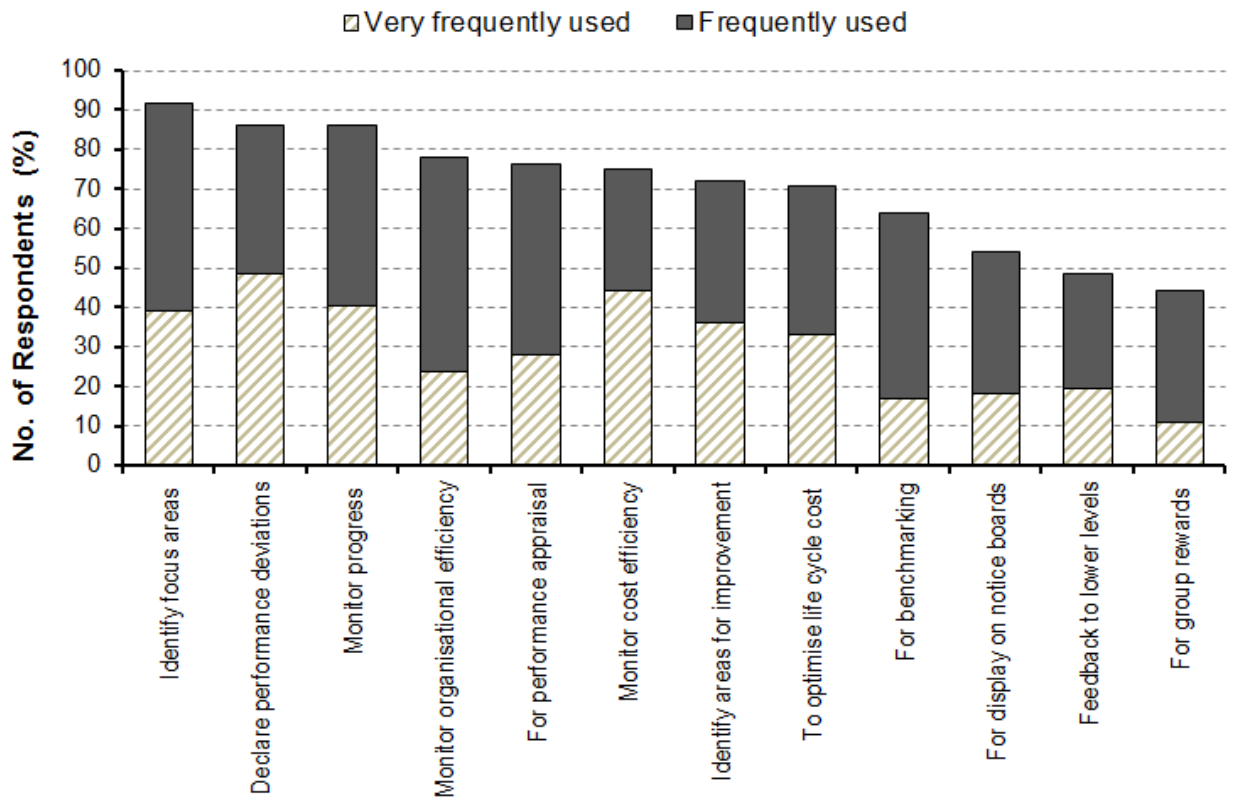

Figure 9: Application of maintenance performance indicators

From Figure 9 it is seen that MPIs are mostly used to 'Identify focus areas' for maintenance groups. However, they are also used often to 'Declare performance deviations'. The high ranking of the latter could mean that a blaming culture is present in the organisation. A root cause analysis tool should be used to determine deviations from performance goals or expectations, rather than just looking for someone to blame. As seen in the graph, MPIs are not really used 'For group rewards'. MPIs defined at lower hierarchical levels might be more useful for performance measurement for groups, and possibly for rewards.

\subsection{Communication}

Communication is an essential part of good management, and respondents were therefore asked to indicate the extent of communication of performance indicators to all levels within the organisation. The breakdown of different levels of communication is shown in the bar chart in Figure 10 below.

The data in Figure 10 shows that most respondents (96\%) had formal or informal communication to explain performance measures to maintenance workers. However, only $36 \%$ of the respondents confirmed that 'Structured formal training' was followed to communicate the rationale of the selected MPIs. Since $71 \%$ of the respondents were engineering managers, the question was probably answered with the communication to the next level of supervisors and artisans as their point of reference. 


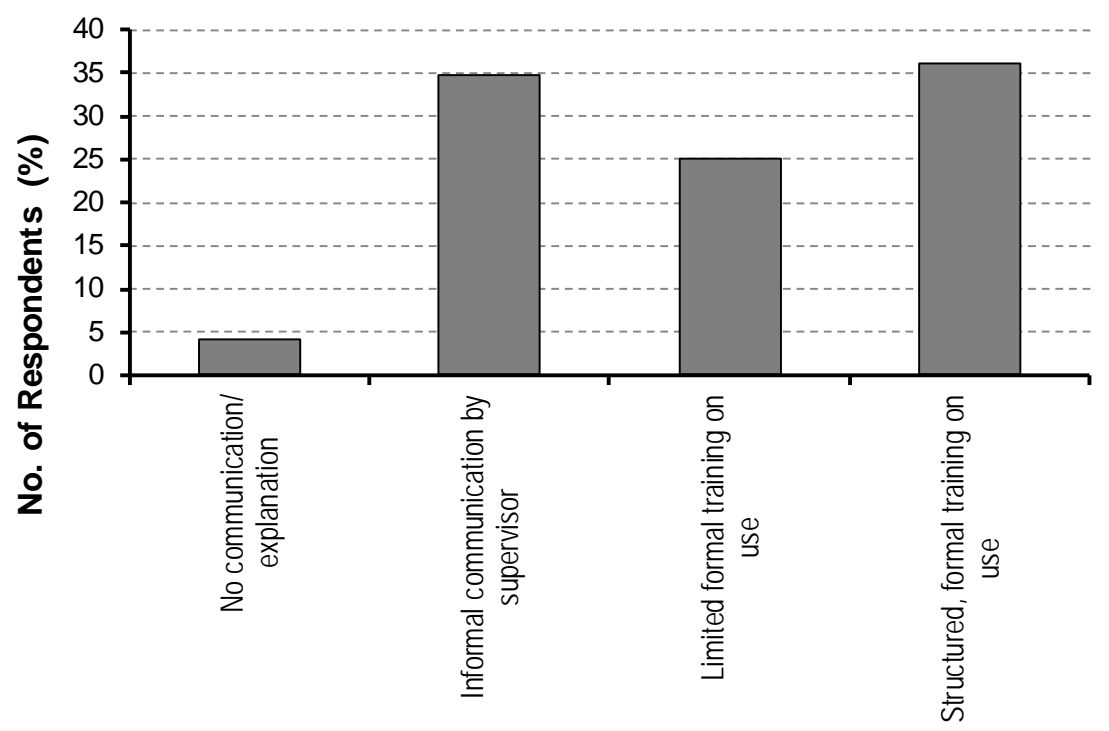

Figure 10: Breakdown of communication levels

\subsection{Indicators for different hierarchical levels}

Managers and supervisors at different hierarchical levels in the maintenance department need different indicators to control the management function. Respondents were asked to indicate whether a 'Structured/formal process' was used to develop MPIs for three different hierarchical levels in the maintenance organisation. Respondents could also select no structured/formal process followed for any level. The results are shown in Table 2.

\section{Table 2: Development of MPIs for different hierarchical levels}

\begin{tabular}{|l|c|}
\hline \multicolumn{1}{|c|}{ Hierarchical level } & Number of respondents (\%) \\
\hline $\begin{array}{l}\text { Structured/formal process followed to identify MPIs for top } \\
\text { management }\end{array}$ & 43.1 \\
\hline $\begin{array}{l}\text { Structured/formal process followed to identify MPIs for middle } \\
\text { management }\end{array}$ & 58.6 \\
\hline $\begin{array}{l}\text { Structured/formal process followed to identify MPIs for first } \\
\text { line management and their teams }\end{array}$ & 31.4 \\
\hline $\begin{array}{l}\text { No structured/formal process followed to identify MPIs for any } \\
\text { level }\end{array}$ & 31.9 \\
\hline
\end{tabular}

As indicated in Table 2 , about $68 \%$ of maintenance departments used a structured or formal process to identify MPIs for at least one hierarchical level of the organisation. Ideally the MPIs should be developed, using a structured process, for all three hierarchical levels.

\subsection{Summary of results}

The results discussed in the previous sections were used to determine whether the propositions of this research could be accepted or not.

Proposition 1: MPIs are not derived or developed from the maintenance strategy and obj ectives through a structured process.

The majority of respondents indicated that MPIs were derived through a structured/formal process, from the company's goals and objectives or from the maintenance strategy. The technically correct processes were thus followed to derive MPIs, and therefore this proposition cannot be accepted. However, there is a concern that respondents indicated that involving employees of all levels in the selection process had a small influence. 
Proposition 2: Maintenance performance management is not applied effectively in the mining industry.

As indicated in Figure 1, effective application of performance management is a function of four elements: purpose of performance management, continuous improvement $(\mathrm{Cl})$, communication of MPIs, and integrity of maintenance data. These four elements were addressed in the survey questions, but the results are not conclusive. The purpose 'declare performance deviations' was ranked second, as seen in Figure 9, but other indicators such as 'identify focus areas' and 'monitor progress' also ranked high; this reflects a positive purpose and application. The purposes 'feedback to lower level employees' and 'to use as rewards for groups' were ranked lowest, which is negative. Although 'structured formal training', as seen in Figure 10, is only done in 36\% of the mines, more than $96 \%$ do use some form of formal and informal communication, which is positive.

The results from the questionnaires are therefore not conclusive enough to accept proposition 2; a more detailed breakdown and larger survey will be required to accept or reject the proposition.

Proposition 3: MPIs used in mining do not address all the important categories of maintenance management.

Most of the popular maintenance performance categories used by respondents are technical measures. The lowest three maintenance categories mostly contain the softer issues of management. Engineering personnel are much more technically-focused than peoplefocused. This is evident from the low measurement of the organisational culture category (including training and employee satisfaction) and customer satisfaction category (which in this case is mostly the operations colleagues). Both these areas are critical in monitoring employee behaviour and motivation. Continuous improvement or innovation is the other category that was used less than the average. These are primarily proactive categories, and have the potential to create value for the organisation. Only $39 \%$ of respondents used indicators from all maintenance performance categories. Therefore, the proposition that not all maintenance management categories are used in performance measurement in the mining industry can be accepted.

Proposition 4: MPIs used in mining maintenance have a high focus on lagging or reactive indicators.

From the data analysed, it was found that most of the frequently-used indicators in mining maintenance were lagging indicators. Six of the top seven indicators are lagging indicators (refer Figure 6). On the other hand, the percentage of leading indicators was very high in the least-frequently-used indicators. One of the primary applications for performance measurement was to declare deviations from operational targets. Given the high focus on lagging indicators in the mining industry, the fourth proposition can therefore be accepted.

Proposition 5: Maintenance performance measurement is not used effectively and efficiently to create value to its fullest potential in the mining maintenance environment.

Two of the first four propositions can be accepted and the other two cannot be accepted from the data obtained. Proposition 5 is a function of the other four propositions, and can therefore not be accepted, given the data obtained by the survey.

\section{CONCLUSIONS AND RECOMMENDATIONS}

The findings of the study are based on the responses from 72 persons involved in the maintenance function within South African mines. The main conclusions that can be made are:

- MPIs used in mining do not address all the important categories of maintenance management.

- MPIs used in mining maintenance have a high focus on lagging or reactive indicators. 
Other conclusions are:

- $\quad$ Some mines derive and develop MPIs from the maintenance strategy using a structured process, but there are some mines that select MPIs from generic lists used in mining.

- Some mines apply maintenance performance measurement effectively and communicate the MPIs to all levels in the hierarchy. But a number of mines do not do this; rather, they use MPIs to declare deviations in performance.

In a specific industry like mining there are always exceptions, and some mines could be applying maintenance performance efficiently and effectively where others do not. The questionnaire was not designed to determine the best or the worst in different areas. A more detailed questionnaire that asks questions related to the lower levels of the maintenance department could identify whether there are large differences between the best and worst performers in maintenance.

Other findings from the research were:

- Mining companies do not use performance management constructively to influence employee behaviour. It seems that the South African mines do not acknowledge the value of employee motivation in performance management through ownership, communication, sense of contribution, and recognition. This is of key importance in overall optimisation and in the improvement process.

- The reactive culture in mining maintenance was confirmed through the extensive use of lagging indicators, reactive maintenance categories, and applying performance management to declare operational and financial deviations.

- Many mines regarded the identification of different MPIs for the different hierarchical levels of the organisations as not important. The effect of this is that managers on the various levels do not focus on areas and actions for their respective roles and timeline.

- Organisational culture (employee satisfaction), customer satisfaction, and continuous improvement (innovation) are three maintenance performance categories that are not managed and driven on the same level as the other categories.

This study adds to the limited research into maintenance performance management and, in particular, into mining maintenance in South Africa. It provides a foundation for further development to change the way performance management is used in the mining industry.

\section{REFERENCES}

[1] De Groote, P. 1995. Maintenance performance analysis: a practical approach, Journal of Quality in Maintenance Engineering, 1(2), pp. 4-24.

[2] Republic of South Africa. Directorate: Minerals Economics. 2007. South Africa's Mineral Industry (SAMI) 2006/2007, http://www.dme.gov.za/pdfs/minerals/sami02006_2007.pdf, ACCESSED on 25 September 2008.

[3] Yager, T.R. 2008. The mineral industry of South Africa, Minerals Yearbook: South Africa, US Geological Survey.

[4] Campbell, J.D. \& Reyes-Picknell, J.V. 2006. Uptime: Strategies for excellence in maintenance management, $2^{\text {nd }}$ ed., Productivity Press, New York.

[5] Tsang, A.H.C. 2000. Maintenance performance management in capital intensive organizations, $\mathrm{PhD}$ thesis, University of Toronto.

[6] Mather, D. 2005. The maintenance scorecard: Creating strategic advantage, New York: Industrial Press.

[7] Tsang, A.H.C. 1998. A strategic approach to managing maintenance performance, Journal of Quality in Maintenance Engineering, 4(2), pp. 87-94.

[8] Wireman, T. 2005. Developing performance indicators for managing maintenance, $2^{\text {nd }}$ ed., New York: Industrial Press.

[9] Mitchell, J.S. 2002. Physical asset management handbook, $3^{\text {rd }}$ ed., Houston: Clarion Technical Publishers.

[10] Parida, A. \& Kumar, U. 2006. Maintenance performance measurement (MPM): Issues and challenges, J ournal of Quality in Maintenance Engineering, 12(3), pp. 239-251.

[11] Kutucuoglu, K.Y., Hamali, J., Irani, Z. \& Sharp, J.M. 2001. A framework for managing maintenance using performance measurement systems, International J ournal of Operations \& Production Management, 21(1/2), pp. 173-194. 
[12] Alsyouf, I. 2006. Measuring maintenance performance using a balanced scorecard approach, J ournal of Quality in Maintenance Engineering, 12(2), pp. 133-149.

[13] Coetzee, J.L. 1997. Maintenance. Pretoria, Maintenance Publishers.

[14] Parida, A. 2006. Development of a multi-criteria hierarchical framework for maintenance performance measurement: Concepts, issues and challenges, PhD Thesis, Luleå University of Technology.

[15] Visser, J.K. \& Pretorius, M.W. 2003. The development of a performance measurement system for maintenance, South African J ournal of Industrial Engineering, 14(1), pp. 83-97.

[16] Kaplan, R.S. \& Norton, D.P. 1996. Using the balanced scorecard as a strategic management system, Harvard Business Review, 74(1), pp. 75-85.

[17] Tsang, A.H.C., J ardine, A.K.S. \& Kolodny, H. 1999. Measuring maintenance performance: A holistic approach, International J ournal of Operations \& Production Management, 19(7), pp. 691-715.

[18] Hedding, R.D. 2005. Measuring maintenance effectiveness: The bulls and the bears, Strategic Asset Management Inc. Available from: http:/www.samicorp.com.

[19] Army, D. 2006. Quantitative and qualitative metrics, The SAMI Times, 7(1) p. 2

[20] Hollhumer, H. \& Visser, J.K. 2008. Quantitative measurement of maintenance performance in the mining industry, Proceedings of the Euromaintenance Conference, Brussels, April 2008. 